\title{
Post-procedural Administration of Nafamostat Mesilate Showed a Similar Preventive effect Against Post- Endoscopic Retrograde Cholangiopancreatography Pancreatitis Compared with Pre-procedural Administration for Patients with Pancreatobiliary Diseases Who underwent ERCP. -A Prospective Double-blind Randomized Controlled Trial
}

\author{
Kei Ito*, Katsumi Kimura, Yutaka Noda, Go Kobayashi, Jun Horaguchi \\ Department of Gastroenterology, Sendai City Medical Center, Sendai, Japan
}

Received: August 01, 2015; Accepted: October 16, 2015; Published: November 19, 2015

*Corresponding author: Kei Ito, Department of Gastroenterology, Sendai City Medical Center, Sendai, Japan, 983-0824, Tel: +81-22-252-1111, Fax: +81-22-252-9431; E-mail: keiito@openhp.or.jp

\begin{abstract}
Aim: To clarify whether post-procedural administration of protease inhibitor can reduce the incidence of post-endoscopic retrograde cholangiopancreatography (ERCP) pancreatitis as effectively as pre-procedural administration.

Patients and methods: Five-hundred and seventy patients who had undergone ERCP-related procedures were included in this study. The patients were randomly assigned to two groups: the postprocedural administration of nafamostat mesilate group (group A, 312 patients) and the pre-procedural administration group (group $B, 258)$. The frequency of post-ERCP pancreatitis was compared between the two groups.
\end{abstract}

Results: The two groups were similar with regard to patient characteristics except for body weight, the frequency of therapeutic procedures, and procedure time. The overall incidence of postERCP pancreatitis was $2.3 \%$. There was no statistically significant difference in the frequency of post-ERCP pancreatitis between groups A and B ( $1.9 \%$ vs. $2.7 \%$, relative risk 0.55 , confidence interval 0.48-4.1)

Conclusion: Post-procedural administration of nafamostat mesilate showed a similar preventive effect against post-ERCP pancreatitis compared with pre-procedural administration.

Key words: ERCP; Pancreatitis; Protease Inhibitor; Nafamostat Mesilate

\section{Introduction}

Endoscopic retrograde cholangiopancreatography (ERCP) is a useful diagnostic and therapeutic modality for pancreatobiliary diseases, but pancreatitis is a serious complication of this procedure. Administration of gabexate mesilate was reported to have been effective for preventing pancreatitis in a prospective randomized controlled trial involving 418 patients; the incidence of pancreatitis was reduced eightfold in the treatment group as compared with the placebo group ( $2 \%$ vs. $16 \%$ ) [1]. Nafamostat mesilate (NM) is reportedly 10-100 times more effective in the inhibition of protease activity than gabexate mesilate[2]. In addition, the half-life period of NM is longer than that of gabexate mesilate (23 minutes vs. 55 seconds), which may be advantageous in terms of drip infusion [3]. In a recent study by Yoo et al.[4], administration of NM before ERCP was found to reduce the frequency of post-ERCP pancreatitis as compared with the placebo group (2.8\% vs. $9.1 \%)$.

Administration of NM for all patients who are to undergo ERCP-related procedures for pharmacological prevention of post-ERCP pancreatitis is a costly treatment strategy. If postprocedural administration of NM can reduce the incidence of post-ERCP pancreatitis as effectively as pre-procedural administration, post-procedural administration of NM can be substituted for pre-procedural administration for prevention of post-ERCP pancreatitis with efficient use of NM only for high-risk patients.

The aim of the present study was to clarify whether postprocedural administration of NM can reduce the incidence of post-ERCP pancreatitis as effectively as pre-procedural administration.

\section{Patients and methods}

\section{Study population}

Between April 1999andMarch2002,ERCP-related procedures were performed in 2134 patients with pancreatobiliary diseases at Sendai City Medical Center. All procedures were performed by five operators with the experience in ERCP in more than 500 cases. Patients 18 years of age or older were enrolled in this 
Post-procedural Administration of Nafamostat Mesilate Showed a Similar Preventive effect Against Post-Endoscopic Retrograde Cholangiopancreatography Pancreatitis Compared with Pre-procedural Administration for Patients with Pancreatobiliary Diseases Who underwent ERCP. -A Prospective Double-blind Randomized Controlled Trial

study. Exclusion criteria were as follows: (1) previous endoscopic sphincterotomy (EST) or endoscopic papillary balloon dilation (EPBD), (2) hyperamylasemia, (3) allergy to NM, (4) emergent case, (5) no informed consent, or (6) pregnancy or breast-feeding.

\section{Study protocol}

Patients who satisfied the criteria were randomly assigned to either the post-procedural administration group (group A) or the pre-procedural administration group (group B) in a double-blind fashion by a third party (nurses). Randomization assignments were performed by the third party before study enrollment by using the block randomization method (block size, 200). They opened sealed opaque envelopes on the day before the procedure, and a patient being allocated to either of the groups following the instruction. Patients were randomized equally to both groups (1:1 allocation), and trial design was parallel type. In group A, patients received infusion of $20 \mathrm{mg}$ of NM for 6 hours beginning within 3 hours after ERCP. In group B, patients received infusion of $20 \mathrm{mg}$ of NM for 6 hours beginning 1-3 hours before ERCP. The details of the drip infusion pattern are shown in Table 1. The dose of NM was decided according to the public insurance rule by the Japanese government for preventing post-ERCP pancreatitis. The endoscopists who performed ERCP and took care of patients after the procedure were unaware of allocation information until the end of the study.

Written informed consent was obtained from all the patients. This study was approved by the Institutional Review Board of Sendai City Medical Center.

\section{Endoscopic procedures and patient care after the procedure}

Before endoscopic procedures, all patients were given a standard premedication consisting of intravenous administration of pentazocine (7.5-15 mg) and diazepam (3-10 mg) or midazolam (3-10 mg), the doses depending on age and tolerance. The procedures were carried out with side-viewing duodenoscopes (JF200, 230, 240: Olympus Medical Systems Co., Tokyo, Japan).

Patients continued fasting after the procedure for a minimum of 18 hours with drip infusion of $2000 \mathrm{ml}$ and remained in the hospital for at least 24 hours. All patients received infusion of antibiotics (cefoperazone-sulbactam, $2 \mathrm{~g} /$ day) for two days. Serum amylase levels (reference range, 54-168 IU/L) were measured before the procedure and 3, 6, and 18-24 hours afterward. Symptoms (abdominal pain, nausea, etc.) and other physical findings such as abdominal tenderness and fever were prospectively evaluated during the hospital stay.

\section{Endpoints}

The primary endpoint was the frequency of post-ERCP pancreatitis. A diagnosis of post-ERCP pancreatitis was made based on the presence of abdominal pain at 18-24 hours after the procedure associated with an increase in serum amylase level greater than three times the upper normal limit. The severity of pancreatitis was classified according to the modified consensus
Table 1: Drip infusion pattern.

Group A

Solita-T No.3 $500 \mathrm{ml}(3 \mathrm{hr})$

Solita-T No.3 $500 \mathrm{ml}+$ NM $10 \mathrm{mg}$ (3 hr) Solita-T No.3 $500 \mathrm{ml}$ (3 hr)

Solita-T No. $3500 \mathrm{ml}+\mathrm{NM} 10 \mathrm{mg}(3 \mathrm{hr})$

\section{Group B}

Solita-T No.3 $500 \mathrm{ml}+$ NM $10 \mathrm{mg}$ (3 hr) Solita-T No.3 $500 \mathrm{ml}$ (3 hr)

Solita-T No.3 $500 \mathrm{ml}$ + NM $10 \mathrm{mg}$ (3 hr) Solita-T No.3 $500 \mathrm{ml}$ (3 hr)

Table 2: Patient Characteristics.

\begin{tabular}{|c|c|c|c|}
\hline No. of the patients & 312 & 258 & ns \\
\hline Age (yrs) & $62 \pm 14$ & $61 \pm 14$ & ns \\
\hline Gender (male:female) & $1.6: \mathrm{I}$ & $1.6: 1$ & ns \\
\hline Body weight (kg) & $61 \pm 12$ & $59 * 11$ & 0.0258 \\
\hline \multicolumn{4}{|c|}{ Diagnoses } \\
\hline Pancreatic cancer & 21 & 21 & ns \\
\hline Chronic pancreatitis & 24 & 22 & ns \\
\hline $\begin{array}{l}\text { Intraductal papillary } \\
\text { mutinous neoplasm }\end{array}$ & 13 & 16 & ns \\
\hline Bile duct stone & 46 & 44 & ns \\
\hline Bile duct cancer & 11 & 15 & ns \\
\hline Gallbladder stone & 125 & 85 & ns \\
\hline Gallbladder cancer & 8 & 7 & ns \\
\hline Other & 64 & 59 & ns \\
\hline \multicolumn{4}{|c|}{ Procedures } \\
\hline Pancreatography & $241(70 \%)$ & $193(75 \%)$ & ns \\
\hline Cholangiography & $\begin{array}{l}241 / 266 \\
\quad(91 \%)\end{array}$ & $197 / 218(90 \%)$ & ns \\
\hline Therapeutic procedures & $82(26 \%)$ & $95(37 \%)$ & 0.0068 \\
\hline Procedure time (min) & $22 \pm 12$ & $25 \pm 13$ & 0.0039 \\
\hline
\end{tabular}

ns: not significant

Table 3: Post-ERCP pancreatitis.

\begin{tabular}{|c|c|c|}
\hline $\begin{array}{c}\text { Group A } \\
(\mathbf{n = 3 1 2})\end{array}$ & $\begin{array}{c}\text { Group B } \\
(\mathbf{n = 2 5 8})\end{array}$ & RR (95\% C.I.) \\
\hline $6(1.9 \%)$ & $7(2.7 \%)$ & $0.55(0.48-4.1)$ \\
\hline Mild, 4 & Mild, 7 & - \\
\hline Moderate, 2 & - & - \\
\hline
\end{tabular}

ERCP, endoscopic retrograde cholangiopancreatography; RR, relative risk; C. I., confidence interval

criteria as mild if prolongation of the planned hospitalization was within 1-3 days, moderate for hospitalizations 4-10 days long, and severe for hospital stays of more than 10 days, as well as in cases with hemorrhagic pancreatitis, phlegmon, or pseudocyst[5].

\section{Sample size calculation}

Based on the pilot study, ${ }^{1}$ the frequency of post-ERCP 
pancreatitis in patients who did not receive infusion of protease inhibitor (PI) was estimated to be $8 \%$, that of post-ERCP pancreatitis by infusion of PI being expected to be $2 \%$. Each group required 277 patients to achieve a $80 \%$ power with type I error rate $(\alpha)$ set at 0.05 . The results were subjected to intentto-treat analysis.

\section{Statistical analysis}

Data were expressed as mean \pm standard deviation. Fisher's exact probability test, Student's t-test, and the Mann-Whitney $\mathrm{U}$ test were used for statistical analyses where appropriate. A $P$ value less than 0.05 was regarded as significant. Statistical analysis was performed with StatMate III (ATMS Co. Ltd., Tokyo, Japan) and StatView Ver.5.0 (SAS Institute, Cary, NC, USA).

\section{Results}

During the study period, 2134 patients underwent ERCP at our institution. Among them, 1564 were excluded from the study due to the following reasons: no informed consent, 869; previous EST/EPBD, 478; emergent case 145; hyperamylasemia, 72. Consequently, 570 patients were enrolled in this study. By means of the sealed envelope method prepared by a third party, 312 and 258 patients were allocated to group A and to group B, respectively (Figure 1).

Characteristics and diagnoses of the patients are shown in Table 2. There was no significant difference in age, gender ratio, success rate of bile/pancreatic ductography, or the diagnoses between the two groups. The mean body weight in group A was significantly higher than that in group $B(P=0.026)$. The mean procedure time in group $A$ was significantly shorter than that in group $B(P=0.0039)$. The frequency of therapeutic ERCP in group A was significantly lower than that in group $B(P=0.0068)$.

Pancreatitis occurred in 2.3\% (13 patients: mild, 11; moderate,
2) of the 570 patients enrolled in this study. In 6 patients of group A who developed pancreatitis after the procedure, the pancreatitis was mild in 4 and moderate in 2 . On the other hand, 7 patients in group B developed post-ERCP pancreatitis (mild, 7). There was no significant difference in the frequency of postERCP pancreatitis between the two groups $(1.9 \%$ vs. $2.7 \%$, relative risk 0.55 , confidence interval 0.48-4.1) (Table 3). All the patients who suffered from post-ERCP pancreatitis improved with conservative therapy.

\section{Discussion}

Since the frequency of post-ERCP pancreatitis is 2-9\% [6-8] prevention of this particular complication is not necessary in the majority of patients who undergo ERCP-related procedures. Although there is a lack of consensus on the pharmacological prevention of post-ERCP pancreatitis with Pis[9-15], administration of such drugs is approved in Japan. Young age, female gender, difficulty of bile duct cannulation, pancreatic sphincterotomy, papillary balloon dilatation, prior ERCP-induced pancreatitis, and sphincter of Oddi dysfunction are considered to be risk factors for post-ERCP pancreatitis[16]. As easily imaginable, proper selection before the procedure of patients at high risk for post-ERCP pancreatitis, other than those of young age and female gender, and those having experienced prior ERCP-induced pancreatitis, is difficult. Administration of PIs for all patients who are to undergo ERCP-related procedures for pharmacological prevention of post-ERCP pancreatitis is a costly treatment strategy.

The present study was conducted to clarify whether postprocedural administration of NM can reduce the incidence of post-ERCP pancreatitis as effectively as pre-procedural administration. The results showed that there was no significant difference in the frequency of post-ERCP pancreatitis between the post-procedural group and the pre-procedural group. Moderate

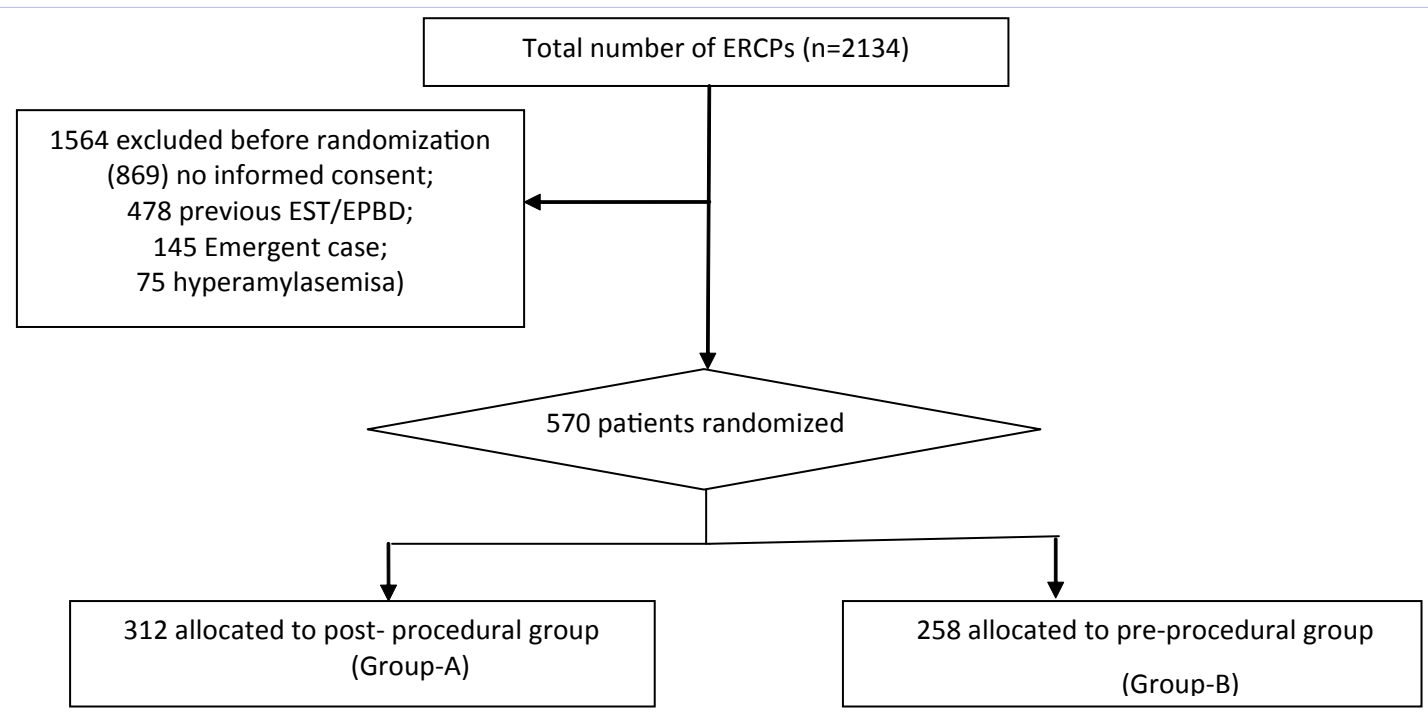

Figure 1: Trial Profile of the study. 
pancreatitis occurred only in 2 patients of the post-procedural group. Although pre-procedural administration of NM may have reduced the severity of post-ERCP pancreatitis, post-procedural administration of NM can be substituted for pre-procedural administration for prevention of post-ERCP pancreatitis with efficient use of NM only for high-risk patients.

Since post-ERCP pancreatitis does not always occur in patients at high risk, early recognition of pancreatic damage after the procedure is indispensable for endoscopists who perform ERCP-related procedures. Testoni et al[17] reported that the level of serum amylase measured 4 hours after EST was the most reliable predictor of post-ERCP pancreatitis, as more than twothirds of cases of pancreatitis occurred among patients whose 4 hours amylase level was higher than five times the normal upper limit. Gottlieb et al[18] found that a 2-hour serum amylase level of less than $276 \mathrm{U} / \mathrm{L}$ (normal: $<114 \mathrm{U} / \mathrm{L}$ ) had a negative predictive value of $97 \%$ in predicting post-ERCP pancreatitis and proposed an algorithm for discharge management after ERCP that incorporated this finding. We have prospectively evaluated the relationship between the changes of serum amylase level and post-ERCP pancreatitis in 1291 patients in a previous study[19]. The frequency of post-ERCP pancreatitis was closely related to the degree of increase in the serum amylase level at $3 \mathrm{~h}$ after the procedure. Therefore, it is expected that the administration of NM based on the serum amylase level can contribute to the efficient usage of NM.

Our study has some limitations. First, the doze of NM (20 $\mathrm{mg} /$ day) was small compared with that in previous studies. The health insurance system of Japan, however, covers the costs of this drug up to $20 \mathrm{mg}$ per day. Second, setting a control group without administration of NM would have been preferable to clarify whether NM can reduce the incidence of post-ERCP pancreatitis. It is, however, out of the scope of the present study. Third, risk factors for post-ERCP pancreatitis as well as the detailed data regarding post-procedural treatment for prevention of pancreatitis could not be analyzed due to 1insufficient data collection. Fourth, there were significant differences in body weight, frequency of therapeutic procedures, and procedure time between the two groups. As mentioned above, multivariate analysis regarding risk factors for post-ERCP pancreatitis could not be analyzed due to insufficient data collection. These differences may have influenced the frequency of post-ERCP pancreatitis. Fifth, the present study was performed more than 10 years ago. The indications for ERCP, endosocpic techniques, and post-procedural treatment in this study may be different from those in present setting. Despite these limitations, our study can be recognized as significant for efficient administration of NM for prevention of post-ERCP pancreatitis. Post-procedural administration of NM for prevention of post-ERCP pancreatitis can contribute to adequate selection of patients and reduction of medical cost.

In conclusion, post-procedural administration of NM did not show inferiority of prevention of post-ERCP pancreatitis compared with pre-procedural administration. Further comparative trials are necessary for establishment of proper usage of PIs for prevention of post-ERCP pancreatitis.

\section{References}

1. Cavallini G, Tittobello A, Frulloni L, Masci E, Mariana A, Di Francesco $\mathrm{V}$. Gabexate for the prevention of pancreatic damage related to endoscopic retrograde cholangiopancreatography. Gabexate in digestive endoscopy--Italian Group. N Engl J Med. 1996;335(13):919923.

2. Iwaki M, Ino $\mathrm{Y}$, motoyoshi $\mathrm{A}$, Ozeki M, Sato T, Kurumi M, et al. Pharmacological studies of FUT-175, nafamostat mesilate: V. Effect on the pancreatic enzyme and experimantal acute pancreatitis in rates. Jpn J Pharmacol. 1986;41(2):155-162.

3. Choi CW, Kang DH, Kim GH, et al. Nafamostat mesylate in the prevention of post-ERCP pancreatitis and risk factors for post-ERCP pancreatitis. Gastrointestinal Endosc 2009;69:11-8.

4. Yoo KS, Huh KR, Kim YJ, Kim KO, Park $\mathrm{CH}$, Hahn T, et al Nafamostat mesilate for prevention of post-endoscopic retrograde cholangiopancreatography pancreatitis: a prospective, randomized, double-blind, controlled trial. Pancreas.2011;40(2):181-186. doi: 10.1097/MPA.0b013e3181f94d46.

5. Cotton PB, Lehman G, Vennes J, Geenen JE, Russell RC, Meyers WC, et al. Endoscopic sphincterotomy complications and their management: an attempt at consensus. Gastrointest Endosc. 1991;37(3):383-393.

6. Masci E, Toti A, Mariani A, Curioni S, Lomazzi A, Dinelli M, et al. Complications of diagnostic and therapeutic ERCP: a prospective multicenter study. Am J Gastroenterol 2001;96(2):417-423.

7. Freeman ML, Disario JA, Nelson DB,Fennerty MB, Lee JG, Bjorkman DJ, et al. Risk factors for post-ERCP pancreatitis: a prospective, multicenter study. Gastrointest Endosc. 2001;54(4):425-434.

8. Vandervoort J, Soetikno RM, Tham TCK, Wong RC, Ferrari AP Jr, Montes $\mathrm{H}$, et al. Risk factors for complications after performance of ERCP. Gastrointest Endosc. 2002;56(5):652-656.

9. Masci E, Cavallini G, Mariani A, Frulloni L, Testoni PA, Curioni S, et al. Comparison of two dosing regimens of gabexate in the prophylaxis of post-ERCP pancreatitis. Am J Gastroenterol. 2003;98(10):2182-2186.

10. Bordas JM, Toledo-Pimentel V, Llach J, Elena M, Mondelo F, Ginès A, et al. Effect of bolus somatostatin in preventing pancreatitis after endoscopic pancreatography: results of a randomized study. Gastrointest Endosc. 1998;47(3):230-234

11. Poon RT, Yeung C, Lo CM, Yuen WK, Liu CL, Fan ST.eProphylactic effect of somatostatin on post-ERCP pancreatitis: randomized controlled trial. Gastrointest Endosc. 1999;49(5):593-598.

12. Poon RTP, Yeung C, Liu CL,C-M Lam, W-KYuen, C-M Lo, etal. Intravenous bolus somatostatin after diagnostic cholangiopancreatography reduces the incidence of pancreatitis associated with therapeutic endoscopic retrograde cholangiopancreatography procedures: a randomized controlled trial. Gut 2003;52[12]:1768-1773.

13. Arvantidis D, Anagnostopoulos GK, Giannopoulos D, Pantes A, Agaritsi R, Margantinis G, et al. Can somatostatin prevent post-ERCP pancreatitis? Results of a randomized controlled trial. J Gastroenterol Hepatol .2004;19[3]:278-282.

14.Andriulli A, Solmi L, Loperfido S, Leo P, Festa V, Belmonte A, et al. Prophylaxis of ERCP-related pancreatitis: A randomized, controlled trial of somatostatin and gabexate mesylate. Clin Gastroenterol Hepatol 2004;2 [8]:713-718. 
15. Tsujino T, Komatsu Y, Isayama H, , Hirano K, Sasahira N, Yamamoto $\mathrm{N}$,et al. Ulinastatin for pancreatitis after endoscopic retrograde cholangiopancreatography: A randomized, controlled trial. Clin Gastroenterol Hepatol. 2005;3[4]:376-383.

16. Dumonceau JM, Andriulli A, Elmunzer J, Mariani A, Meister T, Deviere J, et al. Prohylaxis of post-ERCP pancreatitis: Enropean Society of Gastrointestinal Endoscopy 8ESGE) Guideline -Updated June 2014 Endoscopy .2014;46[9]:799-815. doi: 10.1055/s-0034-1377875. Epub 2014 Aug 22.

17. Testoni PA, Caporuscio S, Bagnolo F, Lella F. Twenty-four-hour serum amylase predicting pancreatic reaction after endoscopic sphincterotomy. Endoscopy. 1993;31[2]:131-136.

18. Gottlieb K, Sherman S, Pezzi J, Esber E, Lehman GA. Early recognition of post-ERCP pancreatitis by clinical assessment and serum pancreatic enzymes. Am J Gastroenterol. 1996;91[8]:1553-1557.

19. Ito K1, Fujita N, Noda Y, Kobayashi G, Horaguchi J,Takasawa O ,et al. Relationship between post-ERCP pancreatitis and the change of serum amylase level after the procedure. World J Gastroenterol. 2007;13[28]:3855-3860. 